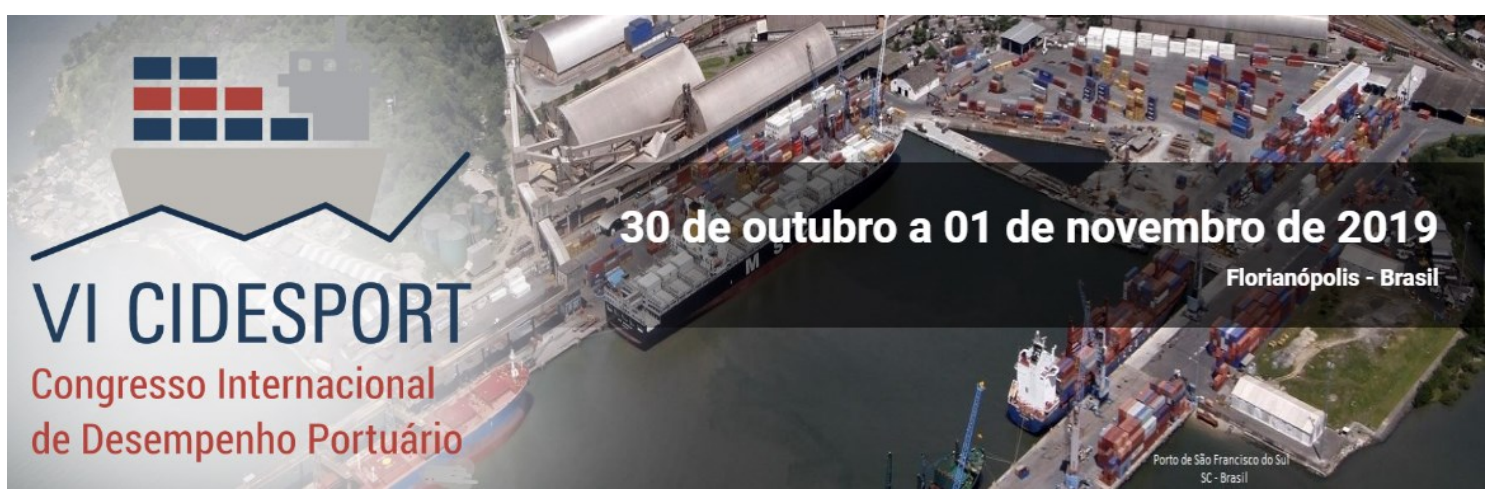

\title{
O RECONHECIMENTO DO IMPOSTO SOBRE SERVIÇOS COMO DESPESA NAS OPERAÇÕES PORTUÁRIAS BRASILEIRAS: UMA ANÁLISE COM BASE NO CASO DE PARANAGUÁ - PR
}

\author{
Amanda Maciel Carneiro \\ Universidade do Estado de Santa Catarina \\ Fabiano Maury Raupp \\ Universidade do Estado de Santa Catarina
}

\begin{abstract}
Resumo: O presente artigo tem por objetivo analisar o reconhecimento do imposto sobre serviços como despesa nas operações portuárias brasileiras, posicionando-se acerca do assunto. Busca compreender os institutos relacionados, elucidando conceitos assumindo uma posição quanto à incidência e base de cálculo. Para atingir esse objetivo, faz-se a análise teórica dos elementos à luz da legislação e dos referenciais teóricos, trazendo também à tona discussão judicial relacionada ao tema e seus reflexos, através de um olhar sobre o caso de Paranaguá - $P R$, município que comporta grande porto público do País. Caracteriza-se o estudo como descritivo e analítico, de abordagem qualitativa, com apoio bibliográfico e documental. A análise fundamenta a conclusão é de que o imposto sobre serviços deve ser reconhecido como despesa nas operações portuárias brasileiras, que essa incidência deve se dar integralmente sobre o preço do serviço, e que isso deve tanto ser considerado nas formação de preço dos operadores portuários quanto deve refletir em seus resultados, respeitados preceitos de justiça social, econômica e tributária e cumprimento de dever cívico e social.
\end{abstract}

Palavras-chave: ISS. Operação portuária. Base de cálculo. Despesa.

\section{INTRODUÇÃO}

A estrutura tributária brasileira é composta de impostos, taxas e contribuições de melhoria (segundo artigo 145 da Constituição Federal vigente), assim como empréstimos compulsórios e contribuições sociais, de intervenção no domínio econômico e de interesse das categorias profissionais ou econômicas (artigos constitucionais 147 e 148) (BRASIL, 1988). Servem esses tributos à realização dos fins do Estado (CARRAZA, 2015), compreendidos como a satisfação dos anseios coletivos e a realização do bem comum (SANTOS, 2006; MARTINS, 2009).

O imposto é a espécie de tributo "cuja obrigação tem por fato gerador uma situação independente de qualquer atividade estatal específica, relativa ao contribuinte", conforme o art. 16 do Código Tributário Nacional (BRASIL, 1966). Para esse estudo, esta é a espécie que será analisada, mais especificamente tratando-se do imposto sobre serviços de qualquer natureza.

O imposto sobre serviços de qualquer natureza é descrito na Lei Complementar Federal (LC) 116, de 31 de julho de 2003 (LC 116/2003), atualizada pela LC 157, de 29 de dezembro de 2016 (LC 157/2016), como aquele que "tem como fato gerador a

\footnotetext{
* A revisão gramatical, ortográfica, ABNT ou APA foi realizada pelos autores.
} 
prestação de serviços constantes da lista anexa, ainda que esses não se constituam como atividade preponderante do prestador", conforme artigo $1^{\circ}$ (BRASIL, 2003). Sua competência constitucional foi dada pelo artigo 156, III, e prevendo-o como imposto devido aos Municípios e ao Distrito Federal, conforme redação do artigo 147 do texto magno (BRASIL, 1988). Substancia-se o imposto em tela parte do arcabouço legislativo tributário brasileiro, sendo a mais importante fonte de receita própria dos entes municipais (MINISTÉRIO DA FAZENDA, 2018).

Como descrito pela LC dispositiva, revestem-se nos campos de incidência do ISS, denominação comum dada ao imposto sobre serviços de qualquer natureza, todos aqueles elencados na lista que segue anexa à lei - lista que compreende hoje 40 itens e cerca de 200 subitens. Dentre os inúmeros serviços abrangidos, destacamse, para fins deste artigo, os elencados no subitem 20.01 , que são os que seguem:

\begin{abstract}
20.01 - Serviços portuários, ferroportuários, utilização de porto, movimentação de passageiros, reboque de embarcações, rebocador escoteiro, atracação, desatracação, serviços de praticagem, capatazia, armazenagem de qualquer natureza, serviços acessórios, movimentação de mercadorias, serviços de apoio marítimo, de movimentação ao largo, serviços de armadores, estiva, conferência, logística e congêneres. (BRASIL, 2003).
\end{abstract}

As operações portuárias, neste sentido, encontram-se no rol das atividades dentre as quais é devido o referido imposto - para fins deste estudo, cumpre esclarecer que o termo aqui utilizado "operações portuárias" faz parte dos descritos acima, e mantém relações estreitas com outros serviços portuários como os de armazenagem, por exemplo. Todos os elencados fazem parte dos denominados "serviços portuários" mencionados no item 20 da mesma lista anexa (BRASIL, 2003).

Assim, sendo as operações realizadas no Brasil ou para o Brasil, incluindo também aquelas que cuja prestação se tenha iniciado no exterior do País, conforme redação do artigo $1^{\circ}$, parágrafo $1^{\circ}$ da LC 116/2003 (BRASIL, 2003), bem como os "serviços desenvolvidos no Brasil, cujo resultado aqui se verifique, ainda que o pagamento seja feito por residente no exterior" (art. $2^{\circ}$, parágrafo único, da mesma LC), certo é que o imposto encontra aí sua legitimação e é devido.

Ainda, pela mesma lei, é o ISS das operações portuárias de competência passiva do próprio operador portuário, já que o "contribuinte é o prestador do serviço" (art. 5, LC 116/2003), impactando diretamente na sua receita e na sua obrigação de recolher os valores devidos aos cofres públicos.

Discussões já se fizeram em torno da base de cálculo do devido imposto, inclusive na seara do Município de Paranaguá, no Estado do Paraná, detentor de um dos maiores portos públicos do País (ANTAQ, 2019). Este foi, então, o caso analisado, utilizado como parâmetro para o deslinde das atividades que englobam a operação portuária, no sentido do descrito pela LC 116/2003, e de como se dá a incidência do ISS nestes casos, com ênfase à base de cálculo. Apresenta-se aqui, então, a base que satisfaz o objetivo de análise do reconhecimento do imposto sobre serviços como despesa nas operações portuárias brasileiras, e que fundamenta o posicionamento dos autores acerca do tema, somada à referência teórica.

Considerando a atuação conforme a norma, a correta formação de preço, a responsabilidade cívica e social do devido recolhimento e as normas de concorrência leal (CAMPANHA, 2010; MARIA; LUCHIEZI JÚNIOR, 2010; SANTOS, 2010; GRECO, 2012; NABAIS, 2012; GODOY; BASSO, 2015), cumpre-nos esclarecer o cabimento do imposto nesses serviços específicos, a fim de que este seja corretamente contabilizado como despesa, inclusive para que a estratégia empresarial o considere 
em sua formação de preço e que os resultados demonstrem de forma contábil claramente a atuação empresarial.

Para cumprir o objetivo proposto, compreende o presente estudo uma estrutura de introdução, apresentando o tema retratado; referencial teórico, aprofundando as bases teóricas das argumentações trazidas à reflexão; procedimentos metodológicos, esclarecendo a metodologia empregada no estudo; resultados, trazendo ao estudo o desenlace da questão; conclusões, com fechamento do assunto e devido posicionamento frente aos elementos estudados; e seguidos, por fim, de referências bibliográficas.

\section{REFERENCIAL TEÓRICO}

A tributação é a maneira pela qual a sociedade contribui com parcela de sua receita própria ao coletivo (MACHADO, 2009; CARRAZA, 2015). Consubstancia-se na principal fonte de financiamento estatal (CARRAZA, 2015), e é essencial para que os fins sociais sejam alcançados - fins esses pacificamente descritos como a satisfação dos anseios, necessidades e vontades da coletividade e a realização do bem comum (SANTOS, 2006; MARTINS, 2009).

No desenho das competências tributárias, a Constituição Federal distribuiu capacidades de obtenção de receitas para fazer frente aos encargos administrativos que os entes foram incumbidos (RUBINSTEIN, 2009; CARVALHO, 2013). Importa para esse artigo a competência constitucionalmente definida aos Municípios de instituição, fiscalização, arrecadação e cobrança do Imposto Sobre Serviços de Qualquer Natureza (ISS), consoante redação do art. 156, III (BRASIL, 1988).

O ISS é definido em sua lei instituidora como aquele que "tem por fato gerador uma situação independente de qualquer atividade estatal específica, relativa ao contribuinte", conforme o art. 16 do Código Tributário Nacional (BRASIL, 1966). Sua história data de antecedentes no Egito, Roma e Grécia (PAIVA, 2005) e mais atualmente, em inspiração na reforma tributária francesa da década de 50 (KORFF, 1977). No Brasil, tem origens legislativas em 1965, mas raízes que datam de 1800, com antigos impostos em atividades lucrativas e profissões, transações e diversões públicas (PAIVA, 2005).

Tem como característica principal o ISS a incidência em serviços descritos na LC 116/2003, federal, cuja instituição cabe aos entes municipais. O fato gerador do imposto é efetivamente o "prestar serviços", dentro, é claro, dos contornos e limites da lei instituidora. De característica marcadamente fiscal (NASCIMENTO, 2010), representa atualmente o ISS a receita própria mais expressiva dos entes municipais (MINISTÉRIO DA FAZENDA, 2018).

Para esse estudo, essencial ainda a redação do artigo $7^{\circ}$ da lei instituidora do ISS: "A base de cálculo do imposto é o preço do serviço." (BRASIL, 2003). Para os devidos fins, esclarece-se a base de cálculo como aspecto quantitativo do imposto, sob o qual incide a alíquota determinada em lei (que, no caso do ISS, varia de 2 a $5 \%$, conforme LC 116/2003) e que possibilita, ao fim, que se determine o valor exato devido pelo contribuinte (ROSSI, 2011).

Traz, ainda, o ISS, em sua lei instituidora, lista anexa contemplando seu campo de incidência, no qual são descritos 40 itens e cerca de 200 subitens nos quais se dão a incidência do imposto (LC 116/2003).

O item 20, que corresponde a "Serviços portuários, aeroportuários, ferroportuários, de terminais rodoviários, ferroviários e metroviários” (BRASIL, 2003), desdobra-se em subitens dos quais nos importa o subitem 20.01,que segue: 
20.01 - Serviços portuários, ferroportuários, utilização de porto, movimentação de passageiros, reboque de embarcações, rebocador escoteiro, atracação, desatracação, serviços de praticagem, capatazia, armazenagem de qualquer natureza, serviços acessórios, movimentação de mercadorias, serviços de apoio marítimo, de movimentação ao largo, serviços de armadores, estiva, conferência, logística e congêneres. (BRASIL, 2003).

Percebe-se, assim, que os serviços portuários englobam o campo de incidência do ISS, com atividades explicitamente relacionadas e campo de interpretação mais amplo dada a expressão "e congêneres", integrando, assim, atividades não explicitamente descritas mas que se referem a serviços portuários, intenção legislativa.

Dentre os serviços portuários descritos, importam-nos as operações portuárias, que são aquelas realizadas pelo operador portuário, "pessoa jurídica pré-qualificada para exercer as atividades de movimentação de passageiros ou movimentação e armazenagem de mercadorias, destinadas ou provenientes de transporte aquaviário, dentro da área do porto organizado", segundo redação da Nova Lei dos Portos, Lei Lei 12.815, de 5 de junho de 2013, em seu artigo $2^{\circ}$, inciso XIII (BRASIL, 2013).

Os operadores portuários são, assim, os titulares e responsáveis pelas operações portuárias que carregam e descarregam as mercadorias no transporte aquaviário. Fazem parte da cadeia do transporte marítimo e do sistema portuário, configurando-se operação complexa, em grande expansão, que corresponde geralmente a grandes volumes de carga e altos valores relacionados (FGV; TCU, 2006; MACHADO, 2016). Para tanto, utilizam de estrutura, maquinário, expertise, logística, capacidade de armazenagem e vários outros elementos da operação portuária (FGV; TCU, 2006) e fazem uso do trabalho de trabalhadores portuários avulsos cadastrados no OGMO, órgão gestor de mão de obra de utilidade pública responsável.

Tem-se como funções típicas portuárias as descritas no art. 40 da Nova Lei dos Portos (BRASIL, 2013), e que são trazidas aqui pela importância do tema e por seu cunho conceitual, como segue:

Art. 40. O trabalho portuário de capatazia, estiva, conferência de carga, conserto de carga, bloco e vigilância de embarcações, nos portos organizados, será realizado por trabalhadores portuários com vínculo empregatício por prazo indeterminado e por trabalhadores portuários avulsos. $\S 10$ Para os fins desta Lei, consideram-se:

I - capatazia: atividade de movimentação de mercadorias nas instalações dentro do porto, compreendendo o recebimento, conferência, transporte interno, abertura de volumes para a conferência aduaneira, manipulação, arrumação e entrega, bem como o carregamento e descarga de embarcações, quando efetuados por aparelhamento portuário;

II - estiva: atividade de movimentação de mercadorias nos conveses ou nos porões das embarcações principais ou auxiliares, incluindo o transbordo, arrumação, peação e despeação, bem como o carregamento e a descarga, quando realizados com equipamentos de bordo;

III - conferência de carga: contagem de volumes, anotação de suas características, procedência ou destino, verificação do estado das mercadorias, assistência à pesagem, conferência do manifesto e demais serviços correlatos, nas operações de carregamento e descarga de embarcações;

IV - conserto de carga: reparo e restauração das embalagens de mercadorias, nas operações de carregamento e descarga de embarcações, reembalagem, 
marcação, remarcação, carimbagem, etiquetagem, abertura de volumes para vistoria e posterior recomposição;

V - vigilância de embarcações: atividade de fiscalização da entrada e saída de pessoas a bordo das embarcações atracadas ou fundeadas ao largo, bem como da movimentação de mercadorias nos portalós, rampas, porões, conveses, plataformas e em outros locais da embarcação; e

$\mathrm{VI}$ - bloco: atividade de limpeza e conservação de embarcações mercantes e de seus tanques, incluindo batimento de ferrugem, pintura, reparos de pequena monta e serviços correlatos. (BRASIL, 2013).

Assim, são funções portuárias consideradas típicas os serviços de estivadores, consertadores de carga, conferentes, vigilantes, capatazia e bloco, acima descritos. Vê-se que estas encontram-se integralmente abordadas no item 20.01 da LC 116/2003, sendo, assim, alvos de incidência do ISS. Até aqui, não há grandes surpresas: assim se fez a vontade legislativa, assim incidem os raios tributantes do ente competente.

Retoma-se aqui ponto crucial do aspecto quantitativo do imposto: a base de cálculo. Conforme mencionado acima, a base de cálculo do imposto é o preço do serviço.

Há, contudo, opiniões diversas de empresas autuadas tendo como base de cálculo o valor integral da operação portuária, e que se manifestaram sobre a ilegalidade da cobrança municipal de ISS tendo como base de cálculo a receita bruta da operação portuária, considerando as despesas da operação que julgavam reembolsáveis, como se atuassem como intermediadores (TJPR, 2017). Especial foco desse estudo se dá à controvérsia e seus diversos entendimentos que foram alvo de questionamentos sobre a base de cálculo incidente nessas operações, e que culminaram em ação coletiva contra o Município de Paranaguá - PR.

Em breve e pontual contexto, o Município de Paranaguá situa-se no Estado do Paraná e comporta um dos maiores portos públicos do País (ANTAQ, 2019), porto esse com atuação marcante na exportação de soja e farelo de soja, consolidando-se como grande operador de graneis agrícolas, mas não somente, haja vista existência de cargas variadas como fertilizantes, contêineres, congelados, derivados de petróleo, álcool, veículos, etc. (APPA, 2019).

Regulamenta o Município de Paranaguá o ISS em sua Lei Complementar Municipal 110, de 18 de dezembro de 2009 (LC 110/2009), atualizada pela Lei Complementar Municipal 208, de 22 de dezembro de 2017 (LC 208/2017). Neste, define seus contornos, e incorpora o item 20.01 da LC 116/2003 integralmente, expandindo-o em subitens 20.01 e 20.05, sendo a diferença a separação do subitem de armazenagem de qualquer natureza em subitem 20.05.

Em seu arcabouço legislativo, espalham-se mandamentos como os de que a base de cálculo é o preço do serviço (art. 18 da LC 110/2009) e de que da base de cálculo não se deduzem despesas, custos agregados, bens ou serviços necessários à produção do serviço da base de cálculo do imposto (art. 18, parágrafo $1^{\circ}$, da mesma lei). Ainda, de que se considera preço do serviço "tudo o que for cobrado em virtude da prestação do serviço, recebido ou não, em consequência da sua prestação, a ele se incorporando os valores acrescidos e os encargos de qualquer natureza, ainda que de responsabilidade de terceiros", conforme art. 20 da mesma lei (PARANAGUÁ, 2009).

Percebe-se, assim, nítido descompasso entre aquilo que legalmente é definido como características de cobrança do ISS pela legislação do Município de Paranaguá, e aquilo que foi defendido pelos operadores portuários, ao se posicionarem favoráveis 
a uma base de cálculo nas operações portuárias menor do que o preço do serviço, em caso a seguir descrito.

Neste sentido, a controvérsia se apresentou em discussão emblemática entre o Sindicato dos Operadores Portuários do Estado do Paraná e a Prefeitura de Paranaguá, na figura de seu Secretário da Fazenda, na qual o primeiro se insurgiu contra cobranças de ISS realizadas sobre o preço total dos serviços de operações portuárias de operadores diversos atuantes no local. A discussão, na esfera judicial, é o caso a ser analisado nesse estudo, a fim de esclarecer eventuais dúvidas que ainda podem existir ao redor do assunto, bem como para embasar a posição dos operadores portuários no reconhecimento dessa receita.

Sobre a justa cobrança dos valores devidos de ISS nas operações portuárias, justifica-se a importância nos elementos que seguem:

A justiça fiscal pode ser entendida como aquela que respeita os ditames constitucionais e os aplica de forma indistinta a todos aqueles que integram o campo de atuação da tributação, e permite o desenvolvimento equilibrado tanto pelo viés social quanto pelo viés de mercado (MARIA; LUCHIEZI JÚNIOR, 2010).

A leal concorrência, pelo ponto de vista tributário, impede que empresas de beneficiem de tratamentos tributários desiguais ao trabalharem com preços menores ou contarem com bases de custos minoradas ante o não pagamento correto de impostos (CAMPANHA, 2010; GODOY; BASSO, 2015).

A obrigação de pagar tributos corretamente, por si, implica tanto obrigação social (SANTOS, 2010; NABAIS, 2012) quanto dever cívico de solidariedade (GRECO, 2012), e resulta em desigualdades econômicas e sociais (GODOY; BASSO, 2015).

O correto cumprimento da legislação contábil brasileira, considerando, dentre outras, normativas do Conselho Federal de Contabilidade (CFC) (CFC, 2019), disposições da Lei das Sociedades Anônimas (BRASIL, 1976) e do Código Civil (BRASIL, 2002), implica, no caso específico, em devidamente reconhecer todas as receitas e despesas em seus livros contábeis, em declarações materialmente verdadeiras e com a correta expressão da saúde financeira da empresa (CFC, 2019). Para a empresa que presta serviços de operação portuária, ainda, implica no cumprimento desses preceitos, e na compreensão de que o ISS deve ser levado em consideração no momento de sua formação de preço.

\section{PROCEDIMENTOS METODOLÓGICOS}

Este estudo tem como objeto empírico a análise do reconhecimento do imposto sobre serviços como despesa nas operações portuárias brasileiras com base teórica abordada em revisão e fundamentado em caso recente que envolveu a Prefeitura de Paranaguá, município portuário do Estado do Paraná, de um lado, e o Sindicato dos Operadores Portuários do Estado do Paraná, de outro.

Quanto aos objetivos, trata-se, assim, de estudo descritivo, com enfoque analítico. A pesquisa descritiva pretende "identificar, relatar, comparar" (RAUPP; BEUREN, 2003, p. 81), mostrando-se adequada ao estudo apresentado. O enfoque analítico é evidenciado na análise do material de apoio, utilizado como base nas referências teóricas e nos resultados apresentados, a fim de permitir análise e apreciação aprofundada do assunto.

Para atingimento dos objetivos, fez-se uso de apoio bibliográfico e documental, consubstanciado tanto em estudos aprofundados e em obras literárias sobre o tema quanto em análise legislativa, bem como de análise de caso recente diretamente 
VI CIDESPORT/2019

Congresso Internacional

de Desempenho Portuário

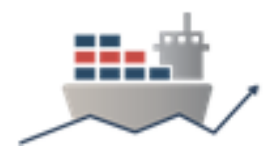

relacionado à posição abordada no referencial teórico, revestido sob a forma de caso judicial.

A abordagem do estudo, por sua vez, é qualitativa, focalizando caso específico para auxiliar na análise fundada em referencial teórico, ampliando a compreensão sobre o assunto e permitindo posicionamento por parte dos autores. Levantaram-se os elementos relacionados e suas interações, a fim de conhecer a natureza e as características do fenômeno social analisado (ALVES, 2003; RAUPP; BEUREN, 2003).

Esclarecidos os procedimentos metodológicos, passa-se agora à análise dos resultados.

\section{RESULTADOS}

A correta compreensão da incidência de ISS nas operações portuárias, a priori, já vem determinada legalmente no corpo legislativo da LC 116/2003, ao relacioná-las no subitem 20.01 de sua lista anexa, bem como a sua base de cálculo, descrita no art. $7^{\circ}$ da mesma lei.

O referencial teórico, dessa forma, esclarece tanto o cabimento do ISS nas operações em questão, devidos à Municipalidade pelo contribuinte-prestador, quanto a impossibilidade de redução da base de cálculo para aquém do preço total do serviço realizado, o que se encontra em consonância com toda a estrutura tributária vigente e com as características elementares do imposto.

De toda sorte, apesar do disposto, tanto o reconhecimento da operação quanto suas características e base de cálculo exigiram análise mais aprofundada ao se reconhecerem tanto posicionamentos diferenciados quanto a estas quanto a necessidade da correta contabilização desse valor.

Para elucidar os conceitos e esclarecer a questão para além da teoria aqui trazida, utilizou-se como base discussão judicial que teve como alvo cobrança de ISS pela Prefeitura de Paranaguá, PR, de operações portuárias por base de cálculo que considerou o preço total do serviço, inadmitidas reduções, e que suscitou em controvérsia judicial, com discussão sobre o tema e posicionamento final acerca da incidência do ISS nessas operações e da base de cálculo correta.

Passa-se, assim, a uma breve análise do caso emblemático de discussão da base de cálculo das operações portuárias que teve como atores uma empresa de operação portuária e a Prefeitura de Paranaguá, PR, e aos seus resultados.

A questão envolvia a consideração ou não da mão-de-obra dos trabalhadores avulsos regidos pelo órgão gestor de mão-de-obra (OGMO) como parte da base de cálculo das operações portuárias, e teve como ponto de partida cobrança administrativa realizada por auditor fiscal da Prefeitura de Paranaguá de valores de ISS a pagar em serviço de operação portuária, considerando a base de cálculo o preço total dos serviços prestados.

Contrariado com a cobrança, o Sindicato dos Operadores Portuários do Estado do Paraná buscou a via judicial para dirimir a discordância, visto que se ressentia da cobrança, dizendo tratarem-se os valores referentes aos serviços executados por trabalhadores avulsos serviços totalmente prestados por terceiros, motivo pelo qual julgavam estar fazendo mero repasse de valores dos armadores, os donos do navio, ao OGMO. Essa discussão se deu através do Mandado de Segurança Coletivo de autos n. 0004844-85-2014.8.16.0129, no Poder Judiciário do Estado do Paraná, Comarca de Paranaguá, Vara da Fazenda Pública (TJPR, 2017). 
Dentre as argumentações trazidas na sentença, algumas obtiveram fundamentação na argumentação da autoridade fiscal responsável pela lavratura do auto, que afirmou, dentre outras, "que o artigo 16 da Lei 8630 (Lei dos Portos) diz que o operador portuário é titular e responsável pela direção e coordenação das operações portuárias que efetuar" (TJPR, 2017, p. 7), ressaltando-se que a mencionada lei foi revogada pela Nova Lei dos Portos, que mantém igual entendimento (BRASIL, 2013).

Outro breve trecho que vale a descrição menciona: "A operação portuária não é serviço contratado por administração; nele não há intermediação, corretagem ou agenciamento" (TJPR, 2017, p. 8), esclarecendo a ausência de relação jurídica entre os trabalhadores avulsos e os armadores ou terceiros (exportadores ou importadores), realizando-se a relação jurídica tão somente entre contratante e operador portuário (quanto à operação portuária), e outra relação jurídica entre operador portuário e trabalhador avulso (para pagamento e realização dos serviços).

Manifesta-se o magistrado no sentido de que os operadores portuários integram as atividades realizadas pelos avulsos às de operação portuária, o que justifica a tributação pelo valor integral da operação (TJPR, 2017).

O trânsito em julgado da sentença se deu em 13/06/2017, confirmando a denegação da segurança pleiteada pelo Sindicato. Em termos de mais fácil compreensão: encerrou-se a discussão judicial com o reconhecimento, pelo magistrado competente, de que a base de cálculo correta para o ISS nas operações portuárias é o preço do serviço, e de que a cobrança administrativa realizada pela Prefeitura de Paranaguá foi feita corretamente.

\section{CONCLUSÕES}

Buscou esse estudo analisar o ISS no contexto das operações portuárias frente à legislação brasileira, a fim de permitir um posicionamento acerca do reconhecimento do imposto sobre serviços como despesa nas operações portuárias brasileiras. Para tanto, trouxe elementos conceituais tanto do próprio ISS quanto das operações portuárias, posicionamentos de doutrinadores, fundamento constitucional e legislação referente ao tema, e trouxe à baila discussões acerca da forma de incidência e base de cálculo a ser adotada nesses serviços.

Importou, assim, esclarecer os institutos envolvidos, com base em referencial teórico sobre o objeto de estudo. Considerando que, a despeito dos ditames legais serem mandatórios acerca do que compõe a base de cálculo, e das características próprias do imposto nortearem sua aplicação e capo de incidência, discussões surgiram acerca da questão, demonstradas em caso base da análise e fonte de posicionamento, revestido em discussão judicial recente que abordou o assunto, rica e esclarecedora.

Do caso protagonizado pela Prefeitura de Paranaguá, no Estado do Paraná, e parte contrária, que representava variadas empresas operadoras portuárias, em discussão acerca da base de cálculo de ISS em operações portuárias, pode-se perceber pelas argumentações e pela sentença o correto cabimento da cobrança estatal. Dali, foram rebatidas as argumentações que desejavam que os valores pagos aos trabalhadores avulsos não ingressassem na base de cálculo do imposto a ser pago pelos operadores portuários.

A sentença afirmou, de forma categórica, que tanto os serviços prestados pelos trabalhadores avulsos quanto quaisquer outros que integrem as operações realizadas são componentes da base de cálculo, cujo valor a ser considerado é o preço total do serviço. 
Assim, da análise realizada, baseados em todo o referencial teórico apresentado e com discussão em caso específico do Município de Paranaguá, PR, pode-se perceber a) a incidência do ISS nas operações portuárias, e b) o preço do serviço como valor a ser considerado integralmente base de cálculo para a aferição do montante devido de imposto.

Isso se deu frente à correta compreensão de que as operações portuárias são mais amplas e compreendem serviços menores por elas englobados e de sua responsabilidade, e de que todos as suas despesas fazem parte da formação de seu preço e não são dedutíveis a fim de reduzir o pagamento de ISS ao ente municipal, como argumentado pelas próprias empresas representadas pelo Sindicato na discussão judicial em tela.

A análise permitiu o posicionamento frente à correta compreensão do tratamento legal do ISS nas operações portuárias, sob essa ótica, ampliando as possibilidades de que sejam respeitados princípios de justiça fiscal e leal concorrência, bem como inibindo, neste caso, o aumento de desigualdades sociais e econômicas.

O devido reconhecimento como despesa, e em seu valor correto, permite, além de tudo, a correta formação do preço e a veracidade dos resultados contábeis da empresa, espelhando assim sua atuação contábil e financeira dentro da legislação vigente do País.

Como estudos de continuidade e aprofundamento, sugere-se o extrapolamento da análise para outras atividades portuárias, a exemplo do agenciamento marítimo, com o qual guarda a operação portuária íntima relação histórica apesar de grande diferença prática. Ainda, vislumbram-se estudos capazes de evidenciarem outros impostos da cesta tributária brasileira e sua correta tributação - já que, na característica de serem também despesas, interferem diretamente na formação de preços das operações portuárias -, a fim de melhor aparelhar o operador portuário em sua estratégia de precificação, além de cumprir com suas obrigações legais.

\section{REFERENCIAS}

ALVES, Magda. Como escrever teses e monografias. Rio de Janeiro: Elsevier, 2003.

ANTAQ (AGÊNCIA NACIONAL DE TRANSPORTES AQUAVIÁRIOS). Estatístico aquaviário. Brasília, 2019. Disponível em: <http://web.antaq.gov.br/Anuario/>. Acesso em: 9 ago. 2019.

APPA (ADMINISTRAÇÃO DOS PORTOS DE PARANAGUÁ E ANTONINA).

Administração dos portos de Paranaguá e Antonina. Paranaguá, 2019.

Disponível em: <http://www.portosdoparana.pr.gov.br/>. Acesso em: 9 ago. 2019.

BRASIL. Constituição (1988). Constituição da República Federativa do Brasil de 1988. Portal da Legislação. Brasília, 1988. Disponível em:

<http://www.planalto.gov.br/ccivil_03/constituicao/constituicao.htm>. Acesso em: 9 ago. 2019. 
VI CIDESPORT/2019

Congresso Internacional

de Desempenho Portuário

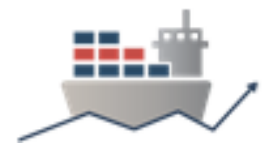

BRASIL. Lei 5.172, de 25 de outubro de 1966. Dispõe sobre o Sistema Tributário Nacional e institui normas gerais de direito tributário aplicáveis à União, Estados e Municípios. Portal da Legislação. Brasília, 1966. Disponível em:

<http://www.planalto.gov.br/ccivil_03/leis/L5172Compilado.htm>. Acesso em: 9 ago. 2019.

BRASIL. Lei n. 6.404, de 15 de dezembro de 1976 Dispõe sobre as Sociedades por Ações. Portal da Legislação. Brasília, 1976. Disponível em: < http://www.planalto.gov.br/ccivil_03/LEIS/L6404consol.htm>. Acesso em: 09 ago. 2019.

BRASIL. Lei n. 10.406, de 10 de janeiro de 2002. Institui o Código Civil. Portal da Legislação. Brasília, 2002. Disponível em: < http://www.planalto.gov.br/ccivil_03/LEIS/2002/L10406.htm> . Acesso em: 09 ago. 2019.

BRASIL. Lei 12.815 , de 5 de junho de 2013. Dispõe sobre a exploração direta e indireta pela União de portos e instalações portuárias e sobre as atividades desempenhadas pelos operadores portuários; altera as Leis nos 5.025, de 10 de junho de 1966, 10.233, de 5 de junho de 2001, 10.683, de 28 de maio de 2003, 9.719, de 27 de novembro de 1998, e 8.213, de 24 de julho de 1991; revoga as Leis nos 8.630, de 25 de fevereiro de 1993, e 11.610, de 12 de dezembro de 2007, e dispositivos das Leis nos 11.314, de 3 de julho de 2006, e 11.518, de 5 de setembro de 2007; e dá outras providências. Portal da Legislação. Brasília, 2013. Disponível em: <http://www.planalto.gov.br/ccivil_03/_ato2011-2014/2013/lei//12815.htm>. Acesso em: 8 ago. 2019.

BRASIL. Lei Complementar 116, de 31 de julho de 2003. Dispõe sobre o Imposto Sobre Serviços de Qualquer Natureza, de competência dos Municípios e do Distrito Federal, e dá outras providências. Portal da Legislação. Brasília, 2003. Disponível em: <http://www.planalto.gov.br/ccivil_03/leis/lcp/lcp116.htm>. Acesso em: 8 ago. 2019.

BRASIL. Lei Complementar 157, de 29 de dezembro de 2016. Altera a Lei Complementar no 116, de 31 de julho de 2003, que dispõe sobre o Imposto Sobre Serviços de Qualquer Natureza, a Lei no 8.429, de 2 de junho de 1992 (Lei de Improbidade Administrativa), e a Lei Complementar no 63, de 11 de janeiro de 1990, que "dispõe sobre critérios e prazos de crédito das parcelas do produto da arrecadação de impostos de competência dos Estados e de transferências por estes recebidos, pertencentes aos Municípios, e dá outras providências". Portal da Legislação. Brasília, 2016. Disponível em: <http://www.planalto.gov.br/ccivil_03/leis/lcp/lcp157.htm>. Acesso em: 8 ago. 2019.

CAMPANHA, Alexssandro. A auditoria tributária como instrumento otimizador da receita própria municipal: a experiência do município de Vitória da Conquista.

Cadernos de Ciências Sociais Aplicadas, Vitória da Conquista, Bahia, n. 9. p. 81108, 2010. Disponível em:

<http://periodicos.uesb.br/index.php/cadernosdeciencias/article/view/881/888>.

Acesso em: 28 abr. 2018. 
VI CIDESPORT/2019

Congresso Internacional

de Desempenho Portuário

CARRAZZA, Roque Antonio. Curso de direito constitucional tributário. 30. ed. rev. ampl. e atual. até a Emenda Constitucional n. 84/2014. São Paulo: Malheiros, 2015.

CARVALHO, Paulo de Barros. Curso de direito tributário. 25. ed. São Paulo: Saraiva, 2013.

CONSELHO FEDERAL DE CONTABILIDADE (CFC). Normas brasileiras de contabilidade. Brasília, 2019. Disponível em: < https://cfc.org.br/tecnica/normasbrasileiras-de-contabilidade/>. Acesso em: 09 ago. 2019.

FGV (FUNDAÇÃO GETÚLIO VARGAS); TCU (TRIBUNAL DE CONTAS DA UNIÃO). Relatório sobre Fiscalização da Regulação Econômico-Financeira: Setor Portuário - Produto 3. Projeto de Aperfeiçoamento do Controle Externo da Regulação do Tribunal de Contas da União - SEFID. Brasília/DF, 21 ago. 2006.

GODOY, Luciano de Souza; BASSO, Juliana Penha. Sonegação e inadimplência contumaz: prejuízo à concorrência empresarial. Revista Digital ESAPERGS, Escola Superior de Advocacia Pública da Associação dos Procuradores do Estado do Rio Grande do Sul (ESAPERGS), Rio Grande do Sul, 2015. Disponível em: <http://www.esapergs.org.br/revistadigital/wpcontent/uploads/2015/07/SONEGA\%C3 \%87\%C3\%830_E_INADIMPLENCIA_CONTUMA Z.pdf>. Acesso em: 02 mai. 2018.

GRECO, Marco Aurélio. Do poder à função tributária. In: ALLEMAND, Luiz Cláudio Silva (Coord.). Direito tributário: questões atuais. Brasília: OAB, Conselho Federal, Comissão Especial de Direito Tributário, 2012. 540p. p. 277-284.

KORFF, Eurico. Finanças públicas municipais. In: Revista de Administração de empresas, Rio de janeiro, ano 1, v.17, n. 5, p. 7-41, set./out. 1977. Disponível em: <http://www.scielo.br/pdf/rae/v17n5/v17n5a01.pdf>. Acesso em: 28 abr. 2018.

MACHADO, Edson Moraes de. A questão portuária nacional: o caso do Estado do Espírito Santo. 2016. 196p. Dissertação (Mestrado) - Universidade Federal de Santa Catarina, Centro de Filosofia e Ciências Humanas, Programa de Pós-Graduação em Geografia, Florianópolis. Disponível em:

$<$ https://repositorio.ufsc.br/xmlui/handle/123456789/168080>. Acesso em: 28 abr. 2018

MARIA, Elizabeth de Jesus; LUCHIEZI JÚNIOR, Álvaro (Orgs.). Tributação no Brasil: em busca da justiça fiscal. Brasília, 2010.

MARTINS, Sergio Pinto. Manual de direito tributário. 8. ed. São Paulo: Atlas, 2009.

MINISTÉRIO DA FAZENDA. Receita Federal do Brasil. Centro de Estudos Tributários e Aduaneiros (CETAD). Carga Tributária no Brasil 2017. Análise por Tributos e Bases de Incidência. Brasília, Novembro de 2018. Disponível em: $<$ http://receita.economia.gov.br/dados/receitadata/estudos-e-tributarios-eaduaneiros/estudose-estatisticas/carga-tributaria-no-brasil/carga-tributaria2017.pdf>. Acesso em: 27 dez. 2018. 
NABAIS, José Casalta. Nota sobre o dever fundamental de pagar tributos. In: ALLEMAND, Luiz Cláudio Silva (Coord.). Direito tributário: questões atuais. Brasília: OAB, Conselho Federal, Comissão Especial de Direito Tributário, 2012. 540p. P. 251-258.

NASCIMENTO, Jair Roberto do. Um estudo sobre a influência das regras e procedimentos de controle fiscal via internet nos resultados da arrecadação tributária de municípios do estado de São Paulo. 2010. 160p. Dissertação (Mestrado) - Faculdade de Economia, Administração e Contabilidade de Ribeirão Preto, Universidade de São Paulo. Ribeirão Preto. Disponível em: $<$ http://www.teses.usp.br/teses/disponiveis/96/96133/tde10122010-151137/ptbr.php>. Acesso em: 02 mai. 2018.

PAIVA, Valfredo. Tributação, arrecadação e política fiscal - um estudo de caso: o Programa de modernização da administração tributária do município de Vitória. 2005. 144p. Dissertação (Mestrado Profissional) - Fundação Instituto Capixaba de Pesquisas em Contabilidade, Economia e Finanças (FUCAPE). Curso de Ciências Contábeis. Vitória. Disponível em:

$<$ http://www.fucape.br/_public/producao_cientifica/8/Dissertacao\%20Valfredo.pdf>. Acesso em: 18 abr. 2018.

PARANAGUÁ. Lei Complementar 110, de 18 de dezembro de 2009. Dispõe sobre as normas relativas ao imposto sobre serviços de qualquer natureza ISSQN e taxas municipais, acrescentando e alterando dispositivos na Lei Complementar n. 06, de 21 de dezembro de 2000, Código Tributário Municipal, e dá outras providências. Leis municipais. Paranaguá, 2009a. Disponível em: $<$ https://leismunicipais.com.br/a/pr/p/paranagua/leicomplementar/2009/11/110/leicomplementar-n-110-2009-dispoe-sobre-as-normas-relativasao-imposto-sobreservicos-de-qualquer-natureza-issqn-e-taxas-municipais-acrescentando-ealterandodispositivos-na-lei-complementar-n-06-de-21-de-dezembro-de-2000-codigotributariomunicipal-e-da-outras-providencias?q=110>. Acesso em: 8 ago. 2019.

PARANAGUÁ. Lei Complementar 208, de 22 de dezembro de 2017. Altera a Lei Complementar n. 110, de 18 de dezembro de 2009, que dispõe sobre as normas relativas ao imposto sobre serviços de qualquer natureza ISSQN e taxas municipais, acrescentando e alterando dispositivos na Lei Complementar n. 06, de 21 de dezembro de 2000, Código Tributário Municipal, e dá outras providências. Leis municipais. Paranaguá, 2017a. Disponível em:

<https://leismunicipais.com.br/a/pr/p/paranagua/leicomplementar/2017/21/208/leicomplementar-n-208-2017-altera-a-lei-complementar-n-110-de-18-de-dezembro-de2009-que-dispoe-sobre-as-normas-relativas-ao-imposto-sobreservicos-de-qualquernatureza-issqn-e-taxas-municipais-acrescentando-e-alterandodispositivos-na-leicomplementar-n-6-de-21-de-dezembro-de-2000-codigo-tributariomunicipal-e-daoutras-providencias?q=208>. Acesso em: 8 ago. 2019.

RAUPP, Fabiano Maury; BEUREN, Ilse Maria. Metodologia da pesquisa aplicável às ciências sociais. In: BEUREN, Ilse Maria (Org.). Como elaborar trabalhos monográficos em contabilidade: teoria e prática. São Paulo: Atlas, 2003. P. 76-96. 
VI CIDESPORT/2019

Congresso Internacional

de Desempenho Portuário

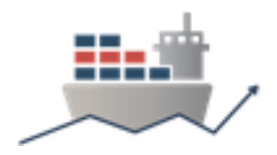

ROSSI, Carlos Alberto Del Papa. ISS - Base de cálculo. In: MARTINS, Ives Gandra da Silva; BRITO, Edvaldo Pereira de (Orgs.). Direito tributário: impostos municipais e contribuições. São Paulo: Revista dos Tribunais, 2011. (Coleção doutrinas essenciais; v.5). P. 251-268.

RUBINSTEIN, Flávio. Repartição de competências tributárias no Brasil sob a ótica da teoria normativa do federalismo fiscal. In: VASCONCELLOS, Roberto França de. Direito tributário: política fiscal. São Paulo: Saraiva, 2009. (Série GVLaw). P. 234289.

SANTOS, Clezio Saldanha dos. Introdução à gestão pública. São Paulo: Saraiva, 2006.

SANTOS, Maria das Graças dos. Políticas públicas: Contribuições para o debate. In: KANAANE, Roberto; FIEL FILHO, Alécio; FERREIRA, Maria das Graças (Orgs.).

Gestão pública: planejamento, processos, sistemas de informação e pessoas. São Paulo: Atlas, 2010. P. 3-16.

TRIBUNAL DE JUSTIÇA DO PARANÁ. Sentença nos Autos n. 000484485.2014.8.16.0129. Poder Judiciário do Estado do Paraná. Comarca de Paranaguá. Vara da Fazenda Pública. Magistrado Rafael Kraemer Braga. Paranaguá, 12 fev. 2015. Disponível em:

<https://projudi.tjpr.jus.br/projudi_consulta/arquivo.do? ttj=8a6c53f8698c7ff7e57a8eff b7e25219fae98c0a4622379321c9e0c91ba7c5c7e9dd0b0b975d50f7> . Acesso em: 9 ago. 2019. 